\title{
1 \\ Focus and Givenness: A Unified Approach
}

Michael Wagner

McGill University

\begin{abstract}
Theories about information structure differ in treating focus-, contrast-, and givenness-marking as either a single phenomenon or as distinct phenomena. This paper argues for a unified approach, following the lead of Schwarzschild (1999), but a unified approach based on local alternatives (Wagner, 2005, 2006b). ${ }^{1}$ The basic insights of the local alternatives approach are captured using a new formalization, which aims to fix several problems in the original proposal noted in Büring (2008). The unified approach is compared with alternative approaches that invoke separate mechanisms for givenness and focus: the disanaphora approach (Williams, 1997), the F-Projection account (Selkirk, 1984, 1995), and the reference set approach in Szendröi (2001) and Reinhart (2006). All of these have fundamental problems, and the requisite revisions render them equivalent to the local alternatives approach.
\end{abstract}

Keywords: alternatives, focus, givenness, prosody, contrast, information structure

1 The label 'local alternatives' for the 'relative giveneness' account in Wagner $(2005,2006 \mathrm{~b})$ was proposed in Rooth (2007) and seems like a more appropriate term. 


\subsection{Three Phenomena, or Two, or One?}

The distribution of accents in a sentence in English is affected by information structure in a systematic way. Information structure comprises a broad set of phenomena. This paper looks at three types of effects that influence the prosody of a sentence, those of question-answer congruence, contrast, and givenness, and presents evidence-some new, some already presented in Wagner $(2005,2006 b)$ - that all three should be treated as reflexes of the same underlying phenomenon.

For the purposes of this paper, I will only consider the location of the last accent in a sentence (marked in small-caps), which can be followed by unaccented or at least heavily pitch-suppressed material (marked by underlining). My examples will not indicate whether and where there are any preceding accents in the sentence. This simplification of the data is not meant to imply that pre-final accents are not relevant or altogether absent, but rather than shifting the final prominence leads to a much clearer perception of focus effects (Breen et al., 2009, and references therein), and hence intuitions are clearer. This may simply be due to the fact that any shift in accent location is perceptually more salient for the location of the last accent, or it may point to a deeper difference in the semantic/pragmatic import of final and pre-final accents-a question that this paper will not address.

One important factor influencing accent placement is question-answer congruence. The last accent of an answer is usually contained in the constituent that corresponds to the wh-word in the question under discussion: ${ }^{2}$

(1) Question-Answer Congruence (Sentence Focus)

A: Who arrested Smith?

B: The DETECTIVE arrested Smith.

A second factor is contrast. If there is an expression that is partially overlapping and partially contrasting with a previous expression, then accent placement is often affected:

(2) Contrast

A: Did the policeman arrest Smith?

B: No, the DETECTIVE arrested Smith.

${ }^{2}$ I will henceforth make the common assumption that the focus of a sentence is determined by the 'question under discussion,' which can be set by an explicit question in the context. The appropriate answer to a wh-question has sentence-focus on the constituent corresponding to the wh-word. I will sometimes use focus particles to control the breadth of focus, since it often cannot be excluded that a response to a question might actually shift to a different question under discussion, which raises problems for the usual methodology of using a question to control focus. 
A third factor is givenness. Accent placement can change if a constituent that otherwise would have borne the last accent refers to an individual or entity that has already been introduced to the discourse:

(3) Givenness

A: Smith walked into a store. What happened next?

B: A detective ARRESTED $\underline{\text { Smith. }}$

One major point of divergence among various different approaches to information structure is whether these three factors are treated as reflexes of one and the same underlying phenomenon, or whether they receive different explanations.

The first part of this paper looks at apparent differences between givenness on the one hand, and question-answer congruence and contrast on the other, and presents evidence that these differences are in fact illusory. I present a formalization of a unified approach, the local alternatives approach proposed in Wagner (2005, 2006b). It is similar in many ways to Williams (1997), but it crucially differs in treating focus/contrast and givenness marking (including that of pronouns) as a single phenomenon. It also differs in making use of alternatives in stating conditions on prominence shift, rather than merely requiring non-identical sister constituents (but see Williams (this volume) for a way to further restrict the notion of 'sister' in this approach).

The approach presented here is also similar in certain ways to the one proposed in Schwarzschild (1999), who also argues for a unified treatment of the various focus- and givenness phenomena. The main difference to Schwarzschild's approach is its reliance on alternatives, apart from technical differences in how givenness-marking is implemented. This paper does not provide a detailed comparison which would have taken up more space than available.

Two alternative approaches are discussed in the second part of the paper. These approaches both single out cases like (3) and treat them differently from (1) and (2). The first is the Focus Projection approach in (Selkirk, 1995), and the second hte Reference Set Approach in (Reinhart, 2006). Both approaches both under-generate and over-generate information-structure-driven prominence shifts.

\subsection{Conditions on Shifting Prominence}

One way of deriving sentence prosody is to assume with Chomsky and Halle (1968) that prominence relations are negotiated at each syntactic node, such 
that all but one of the sisters is demoted in prominence relative to the one carrying main stress. This recursive procedure is called the transformational cycle.

We can represent prominence, following Liberman and Prince (1977), using binary metrical trees, where either the left-hand or the right-hand sister is marked as strong and the other as weak. The result is a metrical tree that encodes prominence relations. The main prominence of a sentence falls on the node that is connected to the root by nodes labeled as strong (Williams, 1997, 601):

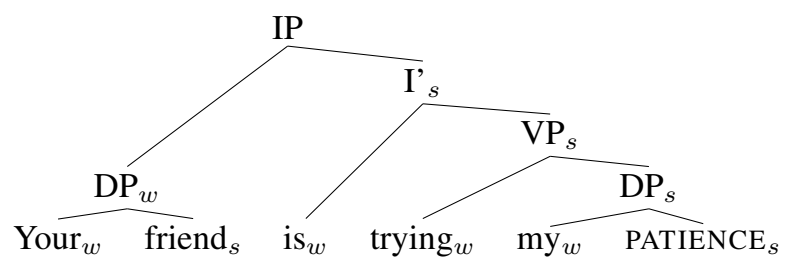

This representation makes a strong and probably false assumption, namely that there are only two possible prosodic relations sisters can have. For example, it would predict that [VO] should have the same prosody independently of whether the $\mathrm{V}$ is marked as given (or the object as focused), or both verb and object are discourse new. This, however, may not be correct, although it is often assumed in the literature. See Breen et al. (2009, and references therein) for evidence that narrow focus and wide focus differ. Another problem for this representation are cases of double focus, where, for example, both adjective and noun are contrasted with a previous adjective-noun combination (see Williams, this volume, for discussion of such cases).

A metrical representation which allows a richer inventory of prosodic relations between sisters, and includes a representation of boundary strength is presented in Wagner (2005). However, assuming the simpler representation of prominence will make the presented approach more comparable to the alternative approaches discussed here and will suffice for the purposes of this paper. The metrical tree is also assumed as a representation of prominence in the theory of information structure effects developed in Szendröi (2001); Reinhart (2006).

The recursive procedure negotiating stress in sentences proposed in Chomsky and Halle (1968) was deemed unable to capture the effects of focus. Chomsky (1971), for example, proposed that the output representation of the transformational cycle can be overwritten, shifting prominence depending on sentence focus. Williams (1997), however, argued that we can capture global in- 
formation structure effects by making local decisions about the prominence between sisters.

Williams (1997) proposes a number of principles negotiating prominence between sister constituents, including conditions that are aimed at capturing information structure effects. The principles are ranked such that higher, more specific principles block more general principles, following the "elsewhere principle' familiar from lexical insertion in morphology and phonological rule application. The 'normal' stress pattern is derived based on the following principles:

(5) Principles deriving 'Normal' Stress pattern:

Weak PO (predictable object)

Weak Clitic

Weak Head

Weak Left

Note that 'weak clitic' and 'weak PO' already make reference to information structure-these are cases that, under the view defended in the present paper, should be subsumed by the more general principle that guides focus-marking.

The normal pattern determines which node is expected to be strong and which one weak. This normal pattern can be overridden sometimes and the opposite prominence relation, the 'special pattern,' ensues. The principle guiding the possibility of the special pattern is the following (Williams, 1997, 604):

(6) Disanaphora law

In the special pattern

a. the weak element is necessarily anaphoric.

b. the strong element is disanaphoric.

The strong element $x$ is disanaphoric if there is an antecedent of the form $\left[x^{\prime} y^{\prime}\right]$, where $y$ is anaphoric to $y^{\prime}$ and $x^{\prime}$ it is not anaphoric to its correspondent in the antecedent, that is, if it is not identical or 'entailed' by it. ${ }^{3}$

The special pattern is an anaphor, and it is obligatory when possible due to the principle Don't overlook anaphoric possibilities. Shifting prominence to the subject, for example, involves switching prominence at the top node:

(7)

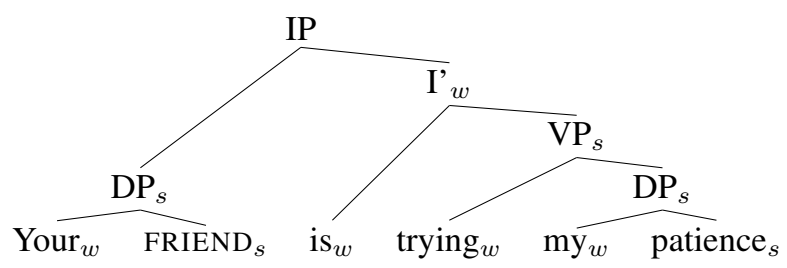

${ }^{3}$ In Williams (this volume), the condition is formulated as non-identity. 
In Williams's theory, the only information necessary to compute the prominence at any given node is information about the two sisters that it dominates. There is no global condition on focus that overrides a decision made locally. If this indeed is sufficient information, it means that information-structural effects can be computed within the same locality domain as the normal stress pattern computed by the nuclear stress rule. So this theory makes focus effects compatible with the general idea that a sentence should be computed recursively on sister nodes, as proposed in Chomsky and Halle (1968).

We will see that Williams's account cannot handle all the relevant data and has to be revised on two counts: (i) the disanaphora is too weak, and must be reformulated in such a way that it makes reference to alternatives; (ii) the principle 'weak PO' should be abandoned, and givenness destressing should be accounted for by the same tool as focus-marking more generally. The locality of negotiating stress, however, is a very attractive feature of Williams's theory, and one that the account given here and in Wagner (2005) strives to maintain.

The three different information structure factors discussed in this papergivenness, contrast, and sentence focus-can all shift prominence relations in a sentence. They seem to differ from each other in their semantic import, and also in how locally their application can be evaluated. These differences will be argued to be only apparent, and that, contrary to the proposals in Williams (1997); Selkirk (1995), and Reinhart (2006), the three cases should be treated as one and the same phenomenon.

\subsubsection{Linguistic Antecedence vs. Presupposed Truth}

Some theories of focus (e.g., Geurts and van der Sandt, 2004) hold that sentence focus involves an existential presupposition:

(8) FRED robbed the bank. Presupposition: Someone robbed the bank.

In other words, focus encodes assumptions about what the speaker considers to be shared knowledge between him and the listener(s), i.e., it encodes an assumption about the common ground (Stalnaker, 1978, 2002). The common ground is often modeled as a set of possible worlds, the context set $C$.

If true, this is a potential difference to giveness-marking, since for the purposes of givenness-marking it seems to be sufficient that a discourse referent or linguistic material is salient in the discourse context, but no particular assumptions about the truth of any proposition seems necessary.

The idea of an existential presupposition for sentence focus runs into many problems, however, when considering entailment relations between sen- 
tences and their focus antecedents. Consider the following example (Sauerland, 2004):

(9) Who, if anyone, ate the cookie?

If sentence focus introduced an existential presupposition, then this question should be infelicitous. See further arguments in Kratzer and Selkirk (2004) and Jacobs (2004).

In the context of givenness-marking in the psychological literature, presuppositions about the truth value of certain propositions are sometimes discussed using the terminology of 'given' and 'new,' conflating two orthogonal dimensions. For example, Haviland and Clark $(1974,513)$ discuss the following example:

(10) Elizabeth tells awful jokes too.

Given: Someone tells awful jokes.

New: Elizabeth tells awful jokes.

The sentence presupposes that someone tells awful jokes, and this piece of information is taken to be 'given' in the sense that its truth is taken for granted. It is important to realize, however, that the notion of 'givenness' at stake in (10) is completely orthogonal to the notion of 'givenness' that we need in order to explain information-structural effects on prosody. For information-structural effects on prosody it is neither sufficient nor necessary that a truth-conditional presupposition is satisfied, a point already made in Allerton (1978), but worth revisiting since even recent approaches sometimes conflate presupposition and givenness.

Consider the case of factive verbs like realize, which introduce the presupposition that the sentence they embed is true. If read out aloud without further context than the one listed, the embedded sentence is usually accented as in (a). Prosodically subordinating the embedded sentence as in (b) is possible, but requires making further assumptions about what's discourse given:

(11) Mary wanted to go swimming in the lake.

a. She didn't realize that it was too COLD.

b. ?? She didn't REALIZE that it was too cold

Things change when the fact that it was too cold to swim is explicitly mentioned in the context, in which case prosodic subordination becomes strongly preferred:

(12) Although it was way too cold, Mary wanted to go swimming in the lake. 
a. \# She didn't realize that it was too COLD.

b. She didn't REALIZE that it was too cold

Although in both dialogues there is a presupposition that it is too cold to swim, it is required to mark this information prosodically as given only when this fact is discourse-salient. So for the purposes of prosodic givenness-marking it is not sufficient that something is true and part of the common ground in order for it to count as given. It is also not necessary for a proposition to be true in order to license its prosodic givenness-marking:

(13) Contrary to the facts, they told her the lake was too cold and it was impossible to swim in it.

a. \# She never believed that it was too COLD.

b. She never BELIEVED that it was too cold

While the approaches discussed in this paper are all well aware of this difference between prosodic givenness-marking and presupposing the truth of propositions, some theories of focus try to model sentence focus (Geurts and van der Sandt, 2004) or even givenness-marking (Sauerland, 2004) positing an existential presupposition, but this leads to a meaning of prosodic marking of focus and givenness that both over- and undergenerates.

A striking illustration of the difference between presuppositions about what is true with presuppositions about what is salient are cleft structures:

(14) It was OLIVIA who kissed Oscar.

Clark and Haviland (1977) argue that a sentence like this, the information someone kissed Oscar is given and the clefted information is what's new, and that further more this goes along with prosodic focus, which also tracks what's given and new. But the presupposition introduced by the cleft is a presupposition about something that has to be true: The sentence entails that some unique person kissed Oscar, and this entailment survives negating the cleft, which is usually taken as an argument that it is a presupposition:

(15) It wasn't Olivia who kissed Oscar $\rightarrow$ Someone kissed Oscar.

If Clark and Haviland (1977) were right and both prosodic focus and clefting are about the same kind of givenness, then we would expect that clefts always need to be pronounced with a prominent clefted constituent. While this may be true as a tendency, it is by no means always true. Consider the following example:

(16) The bank robbers left in a rush. It was the youngest one who drove the van. 
When reading this sentence aloud, speakers do not tend to deaccent who drove the van, contrary to what Clark and Haviland (1977) would seem to predict. The reason is simply that who drove the van is not salient in this context. The cleft can be used because Someone drove the van is easily accommodated and added to the common ground. Despite of the fact that the truth of the presupposition is accommodated and can be added to the common ground (which Clark and Haviland (1977) confusingly call 'given'), this does not mean that it constitutes given information for the purposes of prosodic givenness-marking.

The same point can be made based on the noun phrase the van. The definite article can be used here not because we already knew beforehand that there was a unique van, but because it is easy to accommodate that if there was a van there was exactly one van that the bank robbers used to escape. But that doesn't mean that the van will be deaccented as given. Clark and Haviland (1977) both call definite noun phrases 'given' (but here 'given' actually means that the existence and uniqueness of the referent is presupposed and taken to be part of the common ground) and deaccented noun phrases as well (but here 'given' actually means that they have to be salient in the context, they don't have to be unique or even existing!). The uniqueness presupposition of definite noun phrases is often satisfied by word knowledge: The/\# A sun is rising., but of course, DPs like the sun are not always discourse salient. And in those cases like the sun in which uniqueness is satisfied by world knowledge, then definite noun phrases are perfectly happy to encode discourse new constituents. It is only case where uniqueness cannot be established from previous knowledge (I read the book) that there may be a tendency for definite noun phrases to be deaccented: I couldn't use this sentence if I hadn't introduced a particular book first in the discourse and thus justified using the definite determiner.

Conflating these two completely orthogonal dimensions, presupposed truth and presupposed salience, makes it impossible to properly understand how they work and how they interact. While it is possible to analyze prosodic prominence shifts just like definiteness or the condition in clefts as presuppositional, care has to be taken to do this in such a way that does not washes out existing differences in what types of antecedents these presuppositions are looking for: the definite determiner and the cleft look for an antecedent in the common ground, that the set of propositions currently accepted as true; prosodic focus marking looks for an antecedent among the currently salient linguistic material.

The generalization about prosodic givenness and focus-marking all require reference to antecedents of linguistically explicit material, and are similar in this respect to cases of surface anaphora such as ellipsis, as discussed in Hankamer and Sag (1976). VP-ellipsis, for example, is possible if there is a suitable 
antecedent VP in the discourse, but it is not necessary that there be any true statement involving or entailing the VP. So, just like shifting prominence, it places a condition on what kind of linguistic material should be salient, but, just like prominence shifts, it does not restrict the context set in the sense that it presupposes the truth of the proposition that provides the antecedent:

(17) A: Did anyone drop the ball?

B1: JANE did.

B2: NO ONE did.

To conclude, prosodically marking a constituent as given by shifting prominence requires that an appropriate antecedent is either salient or can be constructed from material salient in the current discourse. The relevant set the antecedent has to be part of is crucially not the set of true propositions taken to be shared knowledge in the conversation, the context set $C$.

I will assume in the following that there is a discourse set $\Delta$ which contains all salient linguistic material, including previously used linguistic constituents, but also indices to discourse-salient entities such as individuals and facts. ${ }^{4}$ Shifting prominence reveals assumptions about what kinds of antecedents are taken to be part of the discourse set $\Delta$, but it does not by itself restrict the context set $C$, i.e., it does not (necessarily) relate to assumptions about the common ground.

This does not necessarily preclude a presuppositional approach to givenness-marking. As argued in Sauerland (2004) and Wagner (2005), the advantage of a presuppositional approach to prosodic prominence shifts is that the fact that givenness- and focus-marking are obligatory when possible can be derived from the independently motivated principle 'maximize presupposition' (Heim, 1991). No additional principles have to be invoked. Alternative ways of capturing the obligatoriness of givenness and focus-marking are the principle 'Don't overlook anaphoric possibilities' of Williams (1997) and the 'Attentiveness Maxim' of Schwarzschild (1997). A more technical approach which is less tied to general pragmatic principles are the constraints favoring minimizing syntactic F-marking as proposed in Jacobs (1991) and Schwarzschild (1999), or the cross-derivational economy condition in Reinhart (2006).

\subsubsection{Compatibility with Wide Sentence Focus}

One apparent difference between (1-2) and (3) regards the overall sentence focus: the case of (3) has an unaccented final constituent and yet the utterance

4 I will assume that $\Delta$ is simply the set of all salient constituents and entities, although the proposal is in principle compatible with a more elaborate theory of discourse representation such as DRT (Kamp, 1981; Heim, 1982) or centering theory (Walker et al., 1998). 
is compatible with sentence-wide focus. In the examples involving contrast and question-answer congruence the focus seems to be narrow, comprising only the sub-constituent bearing the accent. In the case of question-answer congruence, sentence focus is affected by definition, but an interesting question is whether givenness- and contrast-marking differ on this dimension. If yes, is this not already a sufficient reason to draw a line between the phenomena?

According to Chomsky (1971) and Jackendoff (1972), any diversion from the 'neutral' prominence pattern requires that there must be narrow focus on the constituent carrying main stress. However, this does not seem quite right, as illustrated by the case of givenness-marking (3). Often it is sufficient for material to be 'given' or 'thematic' in order for it to be deaccented, while the resulting prosody is still compatible with a wide-focus question. This is a well-known phenomenon, especially in the case of referring expressions, and was discussed in Bierwisch (1966a); Kiparsky (1966), Halliday (1967), Ladd (1980), Höhle (1982), Selkirk (1984), Gussenhoven (1984) and many other studies.

Cases where a referring expression refers back to something that's already salient in the discourse are by no means the only type of case in which a diversion from the normal pattern is compatible with wide focus. Consider the following example of contrast-marking (Rooth, 1992):

\section{(18) An AMERICAN farmer was talking to a CANADIAN farmer...}

Here, the antecedent for the accent omission on farmer is within the same sentence. The entire sentence can certainly have wide focus, even if there may be an embedded contrastive focus within the two NP arguments.

To test whether or not wide focus on a constituent is possible, we can use an exclusive particle such as only in order to control the size of the focus. By looking at which alternatives are excluded, we can probe how broad the focus is that only associates with. Association with focus is a useful tool, since it using a context such as What happened? is not sufficient to assure that the answer has wide sentence focus. It is quite possible that the answer actually has a more narrow focus than the question under discussion, and the speaker expects the hearer to accommodate that he is answering a more specific question.

Using association with focus as a test, we see that even with marked prominence wide association with focus is possible, a point also made in Williams $(1997,607)$. For example, even if an adjective in an NP carries contrastive focus, the entire NP can still be the focus that only associates with (Wagner, 2006a):

(19) Many students in the program are in trouble because of the language 
requirement, even though they know some foreign language. The requirement explicitly calls for knowledge of Latin or Russian. Jim only knows Ancient Greek. So he was told to either drop out or take Latin classes. And he's not the only one who is in trouble.

a. Mary only knows MODERN Greek.

b. ?? Mary only knows MOdERn GREEK.

So she's got the same problem. She'll have to learn Latin.

One interpretation of this observation is that the NP contains an embedded focus-marking, in addition to the focus-marking on the entire NP. This additional embedded contrast is motivated by the antecedent Ancient Greek. No matter how one analyzes what is going on here, the association of the entire NP with only shows that wide focus on the NP is possible with the marked prosody. We can try to use the same test on VPs with unaccented direct objects:

(20) In order to pass this class, you had to present or review an article, and you had to write a final squib. Bill only reviewed an article. So he didn't pass, since he didn't write the squib. And similarly Maria:

a. She only PRESENTED an article.

b. ? She only presented an ARTICLE.

So she also didn't pass, since she didn't write the squib.

Most people I asked disprefer (20b), but it may be possible. Maybe the speaker has a choice here of whether or not to mark the contrast with the antecedent. The important point is that (20a) is possible. It seems that leaving the direct object unaccented is compatible with wide focus on the VP-as long as there is an appropriate antecedent motivating the shifting of prominence, as there is in the present context. If the focus that only associates with in this example was just presented (as opposed to review), then the meaning of (20a) should be equivalent to that of (20b). But that seems odd in the present context, since it wouldn't validate the inference finally drawn, namely that she didn't pass. ${ }^{5}$

So both contrast-marking and givenness-marking are compatible with wide focus. In both cases the marked accentual pattern introduces a requirement on the discourse: they introduce the condition that there be a certain kind of salient antecedent, i.e., an antecedent that is in the discourse set $\Delta$, motivating the shift in prosody.

5 This is complicated judgment, and it would be better to investigate this more systematically, which I hope to do on a future occasion. Thanks to an anonymous reviewer for comments that helpted to refine the example. 


\subsubsection{Requiring Alternatives}

At first sight, another property seems to differentiate givenness deaccentuation (3) from question-answer congruence and contrast (1-2), and this intuition is probably the major reason why various accounts in the literature have distin-

guished them. In the latter two cases it seems quite clear that alternatives to a particular constituent play a role.

In the case of wh-questions, the speaker asks which one of a range of possible alternatives is the one that needs to be substituted to make the sentence true-even if the alternatives are not explicit in the discourse. In fact, the very denotation of the question is often taken to be the set of possible answers (Hamblin, 1973), which can be construed by substituting those constituents that are focused and introducing alternatives for them. In the case of contrast, it seems like alternatives to the constituent containing the accent must have either been mentioned or are evoked. However, there is no such obvious intuition about alternatives in the case of givenness-marking.

One could argue then that there are two separate conditions that can have the effect that a constituent remains unaccented: one with the effect that an alternative is evoked on the accented material (e.g., contrastive focus), and the other with the sole effect that the unaccented constituent must be salient in the context (e.g., by having been mentioned before). Indeed, this is the stance taken both in the F-projection approach and in the Reference-Set approach, as we will see later on. A closer look suggests, however, that in all of the cases alternatives may be at play.

Let's first consider the case of a prominence shift within NPs. Wagner (2005, 2006b) argues that a shift of prominence from the head-noun to the adjective invokes an alternative on the adjective (more examples confirming this observation are discussed in Büring (2008)).

(21) Sally's uncle, who is incredibly rich and produces high-end convertibles, came to her wedding. I wonder what he brought as a present.

a. Guess what: He brought an blue CONVERTIBLE..

b. ?\# Guess what: He brought a BLUE convertible.

Shifting prominence to the adjective fails, and intuitively it's because blue does not contrast with high-end. The pattern changes if we substitute a different adjective, one that intuitively contrasts with high-end. In this case, the shift in prominence is obligatory:

(22) Sally's uncle, who is incredibly rich and produces high-end convertibles, came to her wedding. I wonder what he brought as a present. 
a. ?\# Guess what: He brought a cheap CONVERTIBLE..

b. Guess what: He brought a CHEAP convertible.

The generalization is that convertible can only be marked as given if there is a plausible antecedent of the form [ $y^{\prime}$ convertible]., where $y^{\prime}$ is a 'proper' alternative to new that contrasts with the adjective in the present utterance.

But what does 'contrast' mean, and what counts as a 'proper alternative'? The set of alternatives for an adjective modifying a noun can be established independently by looking at other utterances that operate on alternatives:

(23) John only likes BLUE convertibles.

The statement in (23) intuitively rules out what John might like yellow convertibles, but it does not impinge upon whether or not John likes expensive or high-end ones. The meaning of sentences involving exclusives such as only further confirms that blue is not an alternative to high-end but cheap is. The characterization of what 'proper' alternatives are will be discussed in section 1.2.5. As a first approximation, we can say that alternatives have to form a partition (Wagner, 2005), i.e., they have to be mutually exclusive, in ways yet to be characterized.

Shifting prominence away from the head noun to an adjective imposes a condition on the context that is stronger than just requiring that the head noun be salient in the context. In an expression that consists of an modifying adjective $x$ and a remaining predicate $y$, shifting prominence to the adjective requires there to be an antecedent of the following shape: There must be an antecedent $x^{\prime} y$ that is salient, and $\left\{x, x^{\prime}\right\}$ have to form or be part of a partition of $y$.

A similar pictures emerges when considering the case of shifting prominence from the VP to the subject of a clause. An unaccented VP invokes an alternative on the subject: ${ }^{6}$

(24) A: Last week class ended early because a physics student pulled the fire alarm in the building. What was the reason this week?

a. B: You won't believe it: A student pulled the FIRE ALARM.

b. \# B: You won't believe it: A STUDENT pulled the fire alarm.

c. B: You won't believe it: A CHEMISTRY student pulled the fire alarm.

Alternatives have to be mutually exclusive. A physics student is not a legitimate alternative to $a$ student, because if we substitute the alternative $a$ physics

6 This is true at least for transitive VPs, but in general subject-stress is default for some but not all intransitive predicates. For discussion of intransitive VPs see Schmerling (1976); Selkirk (1995); Wagner (2005) and Wagner (2007). 
student we do not get a statement that is in any way 'incompatible' with $A$ student pulled the fire alarm. Any description of an individual that is clearly non-identical with the original one in the antecedent, however, would qualify as an alternative (e.g., some OTHER student). The point here is that marking the VP as given requires there to be a 'true' alternative for the constituent to which prominence shifts, just as in the case of within-DP stress-shift.

But what about the case of givenness-marking of a referring expression? In (3), the direct object remains unaccented, and the last accent falls on the predicate. Intuitively, it does not seem that an alternative to 'arrested' is evoked here, and that is also the consensus in the literature. However, omitting the accent on the direct object fails sometimes even though its referent is given:

(25) A:Last week someone shot Smith, the manager of the department store. Today he was finally released from the hospital.

B: So are things back to normal now?

a. ?\# A: No, again, something happened. You'll never guess: (Once again) Someone SHOT/HURT Smith. They had to close again!

b. A: No, something happened. You'll never guess: (Once again) Someone shot/hurt SMITH. They had to close again!

The fact that it is possible to accent Smith is what is crucial here. It is entirely unexpected if a direct object deaccents just by virtue of being given in the discourse. The example contrasts starkly with the original example in (3), where prosodic subordination of Smith is obligatory. In fact, in the present context it seems odd to destress the object. ${ }^{7}$

This failure of shifting prominence provides evidence that omitting an accent on the direct object in fact comes with more strings attached than just that the referent of the direct object has to be given in the discourse. ${ }^{8}$

Let's consider what might be going on here. The sentence that introduces Smith is Last week someone shot Smith. The second sentence is Someone shot/hurt Smith. Here again, entailment relations matter, suggesting that alternatives are at play.

It helps to consider under which circumstances the direct object could remain unaccented. It seems that if we replace someone shot $x$ in the unaccented version with anything else that predicates over Smith and that is not already entailed by someone shot $x$, then leaving Smith unaccented is felicitous:

7 As we will see, the condition on the context introduced by deaccenting a direct object is very weak, so accommodation of an alternative may be possible even in the present example. Although a good indication that the argument is valid is that when asked to read out aloud the dialogue, people spontaneously accent Smith in the present dialogue and deaccent Smith in (3).

8 Related examples were discussed under the heading 'all-given' utterances in Schwarzschild (1999), see discussion below. 
(26) [...] A: No, again something happened....

a. Smith WENT MISSING.

b. Someone KIDNAPPED Smith.

c. Someone stole the KEY from Smith.

d. Someone made ALLEGATIONS against Smith.

e. Someone wrote a scandalous ARTICLE about Smith.

...So they had to close again.

In other words, to license leaving a direct object Smith unaccented in a sentence, there must be an antecedent sentence involving Smith that is 'different enough' from the current sentence, i.e., an alternative is necessary.

This runs counter to the claim in Williams (1997) that it is sufficient that the direct object be 'predictable,' which resulted in the postulation of a separate principle, 'weak PO,' in order to handle these cases.

In contexts like (3), there is an explicit antecedent of the form $\lambda x . p(x)$ [Smith] that is 'different enough' and licenses the prominence shift. But it appears as if that the accent on the direct object can sometimes be omitted even when there is no explicit antecedent in the context to speak of:

(27) What about Smith?

Someone SHOT $\underline{\text { Smith }}$

While a wh-question makes it clear that the answer should be drawn from the set of sentences of the form $\lambda x \cdot p(x)$ [Smith] (or at least those that somehow bear on Smith), it doesn't provide an explicit alternative. However, it is commonly assumed that the very question denotes a set of such alternative assertions that apply to Smith, and even if they are not made explicit, it still seems to be sufficient to provide the antecedent for accent omission.

The same issue arises in the analysis of question-answer congruence in whquestions more generally - and the same response can be given. Consider the following dialogue:

(28) Who shot Smith? JONES $\underline{\text { shot Smith. }}$

The question here does not actually make salient any explicit alternatives, it is merely part of the meaning of wh-questions that there is such an alternative set, and question-answer congruence can be modeled by positing that the answer will pick out the correct ones to make the sentence true. What the relevant alternatives are shas to be partly filled in from context, but also the choice of answer can reveal what the respondent has in mind: If the answer was a plumber 
shot Smith, the excluded alternatives could be answers in which we substitute different professions. The same is going on in the following example:

(29) What kind of bicycle did you buy?

I bought a USED bicycle.

The question does not make salient a specific set of alternatives, it simply presupposes that there is such a set, and asks which of the alternative options makes the sentence true. In the present example the alternative set that the respondent evokes is $\{$ used, new $\}$.

That mere givenness is not sufficient is entirely unexpected in an approach such as Schwarzschild (1999), in which any type of constituent should be able to remain unaccented if it is given in the discourse, including predicates such as bicycle, as long as it minimizes the number of F-markers.

That the condition on shifting prominence is stronger than mere givenness was already observed in Williams (1997), who argued that the sister of a constituent that is anaphorically destressed must be 'disanaphoric.' Williams (1997), however, predicts that any $x^{\prime}$ that is non-identical to the original $x$ suffices, but that, as we saw, is not the case. $\left\{x, x^{\prime}\right\}$ must form part of a set of true alternatives. We will return to the question of what counts as a 'true' alternative in section 1.2.5.

\subsubsection{Evoked Alternatives}

At first sight, it may seem that sometimes, mentioning a predicate such as wine is sufficient to make it given and license a prominence shift to a modifying adjective in the following sentence, without any alternative to its sister being made salient by the context: ${ }^{9}$

(30) A: Shall we bring some wine?

B: Yes, let's bring some FRENCH wine.

However, arguably the respondent is really saying that they should bring French as opposed to, say, Spanish or Italian wine. So maybe the question What kind of wine shall we get?, clearly relevant as a follow up to A's suggestion if B agrees with it, is accommodated here-it's as if someone had asked it, but it was not necessary to say it out aloud because it's quite an expected next step. B's statement suggests that they should choose among French wines and to exclude, say, Spanish and Italian ones.

9 Thanks to Carlos Gussenhoven (p.c.) for this example. 
The strong claim that alternatives have to be salient, however, would become void if accommodation is freely invoked in all cases that look like counterexamples. How can we show that accommodation is really what's going on in (30)? What are the constraints?

Accommodation of an antecedent involving alternatives to French is plausible in (30) based on what we know about wine and how people choose which one they want to drink. In order to show that this is correct, we have to construct examples where we can control the plausibility of the accommodated statement. Consider the following dialogue, where again it seems that a prominence shift is possible without an overt antecedent that makes an alternative salient:

(31) A: John's aunt, who is incredibly rich and owns a bicycle factory, came to his wedding. I wonder what she brought as a present.
a.
B: Guess what: She brought a used BICYCLE.

b. B: Guess what: She brought a USED bicycle.

However, the second answer seems to suggest something in addition to the its literal content, namely that the aunt is cheap-this insinuation is expected if used necessarily invokes an alternative when it carries prominence; an obvious alternative in this case is new. There is some reasonable expectation that she'd bring a new bicycle, given that we just learned that she's rich and owns the factory.

That omitting the accent on the noun indeed invokes an alternative on the adjective is confirmed by the fact that the preferences change when we use an adjective whose alternative would not be motivated by the story:

(32) John's aunt, who is incredibly rich and owns a bicycle factory, came to his wedding. I wonder what she brought as a present.

a. Guess what: She brought a new BICYCLE..

b. ?\# Guess what: She brought a NEW bicycle.

Omitting the accent on bicycle in (32) is only possible if there is a salient antecedent of the form $\left[y^{\prime}\right.$ bicycle]., where $y^{\prime}$ is a 'proper' alternative to new. However, something can be salient without having been mentioned explicitly, in which case the speaker can treat it as part of the discourse set of $\Delta$.

What can be accommodated depends on world knowledge and on information provided by the context. Suppose there is a statement that requires an antecedent that is not actually already salient in the context. The felicity of assuming the salience of that antecedent, of 'evoking' the antecedent without its being part of the discourse set $\Delta$ already, depends on how plausible it is that a 
statement containing the antecedent would naturally come to mind in this context. If the aunt brings a new bicycle, then used bicycle doesn't really come to mind, but if she brings a used bicycle, this violates the reasonable expectation that she would bring a new one, so new bicycle comes to mind quite naturally.

The limits of accommodation of this sort probably tap world knowledge and may not be easily formalizable. It may be that evoking an alternative is only possible when the utterance rules out an alternative assertion containing the alternative-but exploring condition on accommodating an evoked antecedent would require a much broader discussion than is possible here.

\subsubsection{Exclusive Alternatives}

Based on the case of prominence-shift to modifying adjectives, Wagner (2005) suggests that alternative sets have to form partitions. The reason we treat $\{$ highend, cheap $\}$ as alternative modifiers of convertible but not $\{$ high-end, blue $\}$ is that high-end and cheap are mutually exclusive, picking out non-intersecting sets of convertibles, but high-end and blue are not. The former but not the latter form a partition of convertibles.

An adjective does not count as an antecedent if predicating it over the head noun would already entail the contribution of the adjective in the evaluated utterance:

(33) Sally's uncle, who is incredibly rich and produces expensive/luxury convertibles, came to her wedding. I wonder what he brought as a present.

a. Guess what: He brought an expensive CONVERTIBLE..

b. ?\# Guess what: He brought a EXPENSIVE convertible.

If the antecedent is identical (expensive) or a hypernym (luxury), then shifting prominence is infelicitous. Furthermore, it seems that the antecedent can also not be a hyponym:

(34) Sally's uncle, who is incredibly rich and produces expensive convertibles, came to her wedding. I wonder what he brought as a present.

a. Guess what: He brought an luxury CONVERTIBLE..

b. ? Guess what: He brought a LUXURY convertible.

It is possible to not shift the prominence, which suggests that luxury is not considered an alternative without accommodation of further assumptions. If the prominence is not shifted, as in (a), the response seems to suggest that unsurprisingly, the uncle brought an expensive luxurious convertible. What may 
be conveyed by (b) is that he didn't just bring an expensive convertible, he even brought a luxury convertible. This requires the additional assumption of a scale, and intuitively it is the same scale that is involved in the following statement:

(35) He didn't (just) bring an expensive convertible, he brought a LUXURY convertible.

Importantly, what counts as an alternative to an adjective depends on the head nouns. While \{used, new may be an appropriate alternative set if the head noun is bicycle, it is not when the head noun is boyfriend. So it is not possible to stipulate a scale of alternatives for particular lexical items. Rather, we need a condition that defines what counts as an alternative that is sensitive to context and world knowledge.

At least in the case of modifying adjectives, the alternatives seem to have to form a partition of the set denoted by the constituent it modifies, that is, alternatives lead to mutually exclusive predicates. It is easy to see what partitioning means for the denotation of a predicate, since it is a set. A partition is defined as a set of sets that are non-overlapping and whose union is the entire set. But what about the general case when looking at any two sister constituents?

Büring (2008) correctly points out problems with the formalization in Wagner $(2005,2006 \mathrm{~b})$, and suggests a condition that licenses marking $a$ as given relative to $b$ if there is a salient [a b'] such that whether [a b] or [a b'] is an issue. In the following, I propose a different formalization, which has the advantage that it generalizes to the case of givenness-marking.

Rochemont $(1986,47)$ proposes formalizing the notion of antecedence for givenness-marking using the tools of entailment. In this approach a constituent is c-construable (i.e., given) if it is entailed by an antecedent in the discourse: ${ }^{10}$

(36) A string $\mathrm{P}$ is c-construable in discourse $\delta$ if $\mathrm{P}$ has a semantic antecedent in $\delta$.

Having an antecedent in the discourse is defined as follows:

(37) A string $\mathrm{P}$ has a semantic antecedent in a discourse $\delta, \delta=$ $\left\{\phi_{1}, \ldots, \phi_{n},\right\}$, if, and only if, there is a prior and readily available string $\mathrm{P}^{\prime}$ in $\delta$, such that the uttering of $\mathrm{P}^{\prime}$ either formally or informally entails the mention of $\mathrm{P}$.

In Rochemont's theory, a constituent counts as given if it is entailed by an antecedent in the discourse context. The notion of being c-construable is then

10 This definition is later elaborated to account for cases of accommodation (Rochemont, 1986, 63). I will not discuss the details of Rochemont's proposal further. 
used to formulate conditions on focus and givenness-marking. One problem with this notion is that while it is formulated in terms of entailment, not all constituents that are used as antecedents or are marked as given are propositions, so their relationship is characterized as that of an 'informal entailment.'

This issue was addressed in Schwarzschild (1999), who similarly argues that a constituent should count as given if it is entailed by an antecedent in the discourse context, but who proposed a way to type-shift all relevant constituents-i.e., both the antecedent and utterance under evaluation for givenness-marking - into propositions. This is accomplished by an operation of existential type-shifting, ExClo, (Schwarzschild, 1999, 147), which existentially binds unfilled arguments in any expression.

In addition, in Schwarzschild's theory F-marking plays a crucial role. Any constituent that is not F-marked must be entailed by an antecedent in the discourse context. If a constituent contains an F-marked sub-constituent, that subconstituent is replaced by a variable, which in turn is also existentially bound:

(38) Existential F-Closure of U:

The result of replacing F-marked phrases in $U$ with variables and existentially closing the result, modulo existential type-shifting.

A simple illustration:

(39) Antecedent: red convertible

Evaluated Constituent: BLUE $F$ convertible

The following representation is derived:

(40) Antecedent: $\exists x \in C . x$ is a red convertible

Evaluated Constituent: $\exists x \in C . \exists y \in C . x$ is a $y$ convertible

Whether or not a constituent is given is then determined based on entailment: in order for a constituent to be given, it has to be entailed by a salient antecedent in the context. The antecedent in (40) entails the evaluated constituent, so the constraints on givenness are fulfilled.

But note that they would be equally fulfilled if the antecedent contained high-end or even the identical predicate 'blue.' The prediction for the prosody of our example in (21) is therefore that in both cases, prominence would shift. The notion 'alternative' plays no role in the theory proposed in Schwarzschild (1999), but as we saw it is crucially necessary in order to capture the data.

What is needed is a stronger condition. If two modifying adjectives form a partition, then if one holds of the modified constituent then the other is $e x$ cluded: If one predication is true then the alternative predication must be false. 
Suppose we apply universal closure to the constituent under evaluation, and existential closure on the antecedent:

(41) Antecedent: $\exists x \in C . x \in C$ is a red convertible.

Evaluated Constituent: $\forall x, x \in C . x$ is a blue convertible.

Note that now, there is also an entailment relationship between the antecedent and the evaluated constituent, but one that is quite different to the one at play in Rochemont (1986) and Schwarzschild (1999): the evaluated constituent excludes the antecedent.

(42) UniClo(evaluated constituent) $\rightarrow \neg \operatorname{ExClo(antecedent)~}$

Here is the formal definition of Existential closure from Schwarzschild (1999, 199)

(43) Existential Type Shift: ExClo

a. If $\omega \in D_{t}$, then $\operatorname{ExClo}(\omega)=\omega$

b. For any conjoinable type $\langle a, b\rangle$ : If $\omega \in D_{\langle a, b\rangle}$, then $\operatorname{ExClo}(\omega)=$ $\lambda w \exists u \in D_{a}[\operatorname{ExClo}(\omega(u))(w)]$

c. $t$ is a conjoinable type.

If $b$ is a conjoinable type, then so is $\langle a, b\rangle$, for any type a.

Analogously, we can define UniClo as follows:

(44) Universal Type Shift: UniClo

a. If $\omega \in D_{t}$, then $\operatorname{UniClo}(\omega)=\omega$

b. For any conjoinable type $\langle a, b\rangle$ : If $\omega \in D_{\langle a, b\rangle}$, then $\operatorname{UniClo}(\omega)=$ $\lambda w \forall u \in D_{a}[\operatorname{UniClo}(\omega(u))(w)]$

c. $t$ is a conjoinable type.

If $b$ is a conjoinable type, then so is $\langle a, b\rangle$, for any type a.

Finally, we can state the condition on prominence shift as follows:

(45) $\llbracket \mathrm{LEA} \rrbracket=\lambda a \cdot \lambda b . \exists\left[a b^{\prime}\right] \in \Delta . \operatorname{UniClo}([a b]) \Rightarrow \neg \operatorname{ExClo}\left(\left[a b^{\prime}\right]\right): \llbracket a b \rrbracket$

While one can easily apply the condition in (45) to predicates, it does not generalize to cases in which [ab] compose to a proposition, where both universal closure and existential closure do not affect the denotation and simply return the proposition itself. Consider the following dialogue:

(46) A: Mary went swimming.

B: JANE went swimming, too. 
In this case, we are marking a VP as given relative to the subject. The entire constituent is already a proposition, so there is no need to satisfy open argument slots by introducing existential or universal quantifiers. However, clearly the antecedent and constituent under evaluation do not exclude each other. If Jane went swimming this does not entail that it is not the case that Mary went swimming.

What we need is an operator that derives a strengthened statement that would exclude Mary went swimming were it true. Suppose that this operator is a twoplace version of the exhaustive operator proposed in Fox (2006). Exh is essentially a version of only, but differing from it in that it asserts it's prejacent rather than presupposing it:

$$
\begin{aligned}
& \text { Exhaustive Operator } \\
& \llbracket \operatorname{Exh} \rrbracket=\lambda a . \lambda b . \llbracket a b \rrbracket \wedge \forall b^{\prime} \in C: \llbracket a b^{\prime} \rrbracket=1 \rightarrow\left([a b] \Rightarrow\left[a b^{\prime}\right]\right)
\end{aligned}
$$

The condition on givenness-marking in propositions can now be stated as follows: For any node $[a b], a$ can be marked as given relative to $b$ if there is a salient constituent $\left[a^{\prime} b\right]$ in the context such that the exhaustive operator applied to $a$ and $b$ excludes $\left[a^{\prime} b\right]$.

It seems that adding the exhaustive is not necessary to account for the condition on prominence shift in the case of blue convertible, in fact, it seems to lead to the wrong result. I don't see any way at this point to unite the case of focus/givenenss-marking at the proposition level and the sub-proposition level, therefore I define a two-place operator that LEA (for local exclusive alternative) that varies depending on the semantic type of [ab]. I am not sure whether this reflects a deep difference between focus marking at nodes that are not proposition and at the sentence level, or whether this is because the present formalization is flawed. Crucially, all our three cases (1-3) will be handled by the the same operator, all three cases will involve the proposition-level instance of LEA.

The communality is that in both cases it introduces the presupposition that an appropriate antecedent exists in $\Delta$. Presuppositions usually restrict the context $\operatorname{set} C$, but this operator restricts not what is considered true about the world but rather what is salient in discourse.

(48) LEA :

a. If $[a b] \in D_{t}$, then

$$
\llbracket \mathrm{LEA} \rrbracket=\lambda a \cdot \lambda b \cdot \exists\left[a b^{\prime}\right] \in \Delta \cdot \operatorname{Exh}(a)(b) \Rightarrow \neg\left[a b^{\prime}\right]: \llbracket a b \rrbracket
$$

b. Else

$\llbracket \mathrm{LEA} \rrbracket=\lambda a \cdot \lambda b . \exists\left[a b^{\prime}\right] \in \Delta . \operatorname{UniClo}([a b]) \Rightarrow \neg \operatorname{ExClo}\left(\left[a b^{\prime}\right]\right):$ $\llbracket a b \rrbracket$ 
Just like any other presupposition, the presupposition introduced by LEA is subject to the principle Maximize Presupposition, so it has to be encoded if it can be encoded. In other words, when for any two sisters the presupposition introduced by LEA is satisfied, the operator has to be used and the presupposition encoded. The LEA operator has the phonological reflex of shifting the prominence to the second argument, the constituent relative to which the first argument is marked as given.

We now have a formulation of an givenness/focus operator that can deal with every type of examples we discussed. It is a two-place operator, which takes a given constituent as its first argument and a focused constituent as it second argument. The idea that focus/givenness might involve a two-place operator is reminiscent of the idea that there is a focus projection as proposed in Rizzi (1997) which takes a focus the background as its argument and the focus moves to its specifier; similarly Bader (2001) proposes that there is a G-projection which takes a given constituent as its complement and a focused constituent in its specifier. Whether there is really a fixed place in the syntactic hierarchy in which a focus or givenness operator is doubtful, however (Wagner, 2009).

Looking at the case of shifting prominence to the subject, we see that the antecedent that licences a prominence shift has to be ruled out by the exhaustification of the constituent under evaluation:

(49) MARY rode a bicycle.

Exhaustive Closure of the constituent under evaluation:

$\llbracket \operatorname{Exh}(\mathrm{a})(\mathrm{b}) \rrbracket=\llbracket \mathrm{ab} \rrbracket \wedge \forall y \in C . y$ rode a bicycle $\rightarrow$ (Mary rode a bicycle $\Rightarrow$ y rode a bic.)

Antecedent: Sally rode a bicycle.

The Antecedent is Excluded:

$\operatorname{Exh}(\mathrm{a})(\mathrm{b}) \Rightarrow \neg\left[a b^{\prime}\right]$

So Sally rode a bicycle is an appropriate antecedent for the prominence shift in MARY rode a bike.

Just as the existential statement derived by closure is not actually presupposed to be true in Schwarzschild's approach, neither is the universal statement in the present approach. The condition is merely a way of evaluating whether a linguistic constituent qualifies as an antecedent in the discourse, and shifting prominence is felicitous even when the truth of the antecedent is presupposed, as in (46). That said, a context in which an alternative statement is actually 
excluded may well be the default type of context that is accommodated if one hears a sentence with marked prominence out of the blue.

Shifting prominence fails when the antecedent is not excluded by the existential closure of the expression under evaluation:

(50) Constituent Under Evaluation:

A STUDENT pulled the fire-alarm.

Antecedent:

A physics student pulled the fire alarm.

The antecedent for deaccentuation, a physics student pulled the fire alarm, is not excluded, because the exhaustification of $A$ student pulled the fire alarm does not rule that A physics student pulled the fire alarm.

This account involving an exhaustive operator can also deal with prominence shift in a context like 'Who rode a bicycle'-if we assume that asking such a question presupposes the existence of a set of alternatives to the whword, and is available as an antecedent for focus/givenness marking. This will be discussed more in the next section.

Finally, the condition on shifting prominence can also account for givenness-marking of direct objects. This will only work if we assume, as previously motivated, that a direct object marked as given moves to the propositional level leaving an open property behind:

(51) $[[\lambda x$. A detective arrested $\mathrm{x}]$ Smith $]$

We then get the following condition on marking the direct object as given:

(52) A detective ARRESTED $\underline{\text { Smith }}$

Exhaustive Operator applied to constituent under evaluation: $\llbracket \operatorname{Exh}(\mathrm{a})(\mathrm{b}) \rrbracket=\llbracket \operatorname{Exh}(\operatorname{Smith})(\lambda x$. A Detective arrested $\mathrm{x}) \rrbracket=$ $\llbracket \mathrm{ab} \rrbracket \wedge \forall y \in C . y($ Smith $) \rightarrow($ A Detective arrested Smith $\Rightarrow y($ Smith $))$

Antecedent: Smith walked into a store.

The Antecedent is Excluded:

$\operatorname{Exh}(\mathrm{a})(\mathrm{b}) \Rightarrow \neg\left[a b^{\prime}\right]$

This is a very weak condition on the antecedent, and will be fulfilled by essentially any other statement that involves John as an argument, as long as it's not in an entailment relationship with the antecedent. So Someone shot Smith would count as an appropriate antecedent for prominence shift to the verb in Someone hurt Smith. 
It is these cases of givenness in which the approach in Büring (2008) does not generalize. It is unclear why (a) should be an issue but (b) should not:

(53) a. A detective arrested Smith or Smith walked in the store is an issue.

b. A detective arrested Smith or Jones walked into the store is an issue

All the alternatives in (26) do form proper antecedents, since they are excluded by the exhaustive statement. Since the discourse set $\Delta$ not only contains linguistic material, but also discourse-salient entities, even a constituent whose linguistic material is new in the discourse but refers back to the same individual can be marked as given, as is the case with epithets:

(54) I went to see my dentist. I'm going to KILL the butcher.

In order to get the condition on accent omission on the direct object right, it must move and lambda-abstract at the proposition level, such that the alternatives considered are any properties that apply to the same individual or set. Otherwise, the evoked alternative set should necessarily be alternatives to the transitive predicate-but we saw that this is too narrow a condition to impose.

This movement approach to the givenness-marking of direct objects makes a surprising prediction: marking a referring expression as given in a position from which it cannot move to a propositional node should 'trap' it and result in a stronger condition on shifting prominence away from it.

This expectation is confirmed by the implications of accent omission in coordinate structures, as observed in Wagner (2005). Omitting the accent on Smith introduces a condition stronger than just that there is an antecedent for Smith:

(55) Smith was suspected to have been involved in the burglary. Do you know what happened in the end?

a. I' $m$ not sure. The thing I heard last is they were going to arrest JONES or SMITH.

b. ?? ..to arrest Jones OR $\underline{\text { Smith. }}$

c. \# ...to arrest JONES or Smith.

Shifting prominence as in (55b) would be fine in the following context:

(56) Did they arrest only Smith?

No, they arrested Jones AND Smith.

(antecedent constituent: only Smith)

Sentence (55c) requires a contrasting individual for Smith: 
(57) They want to arrest Lee or Smith?

No, they want to arrest JONES or Smith.

(Antecedent: Lee or Smith)

In principle, islands other than coordinate structures should affect givennesspresuppositions in a similar way. But it any propositional node is sufficient to weaken the presupposition in the described way, and givenness movement can take place within the island. So the evidence in favour of movement from islands may remain somewhat tentative.

However, we can add two pieces of evidence for this kind of movement. First, as was pointed out to me by Lisa Selkirk (p.c.), if the proposed analysis is correct then we would expect that given material within DPs should behave differently from given material in VPs, since DPs do not encode propositions (although some refer to events, which might be a sufficient target for the weakening of the presupposition). Consider now a DP like 'a DJ' in a noun phrase like in 58. Deaccenting the DP should require evoking an alternative for presence, since there is no propositional node to move to. However, it is not clear what that alternative should be (absence comes to mind but doesn't seem to be an interesting alternative to consider), and indeed, the preferred pronunciation is with an accent on $D J:^{11}$

(58) a. I recommend hiring a DJ. The presence of A DJ makes a big DIFFERENCE at party.

b. ?\# I recommend hiring a DJ. The PRESENCE of a DJ makes a big DIFFERENCE at a party.

A second argument can be made based on an interaction with language-specific movement constraints and the presuppositions introduced by deaccenting. In English, it is sometimes possible to deaccent the complement of a preposition, without evoking an alternative to the preposition:

(59) A: If you need an ATM, why dont you go to the gas station?

B: I didn't even know there was an ATM AT/IN this place/the gas station.

It is unlikely that there is an alternative to the preposition that is necessarily evoked here, since what would it be and why would it be relevant? The example should be infelicitous indeed an alternative was necessary-as it is actually is in German:

11 A broader range of DPs should be looked at to test this further. the possibility of deaccentuation should correlate with how plausible to accommodate an alternative to the head-noun. 
(60) A: Wenn Du einen Geldautomaten brauchst, warum gehst du nicht

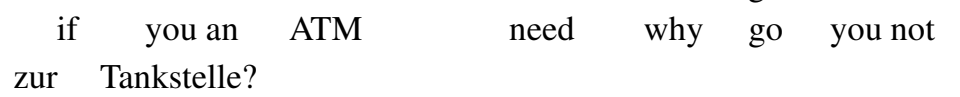

to the gas station

\#-B: Ich wusste ja gar nicht dass da ein Geldautomat

I knew actually at all not that there an ATM

IN/BEI der Tankstelle ist

in/at the gas station is

The observed contrast is just as expected since English allows for preposition stranding and hence movement of an ATM to the propositional node, but German does not. In German, the entire PP has to be deaccented (and it as a whole might move). While this is also possible in English, English has the additional possibility of moving the complement out of the PP. Even in English, however, this pattern of shifting prominence to the preposition is not fully productive, it seems. It is only possible for those prepositions that can also receive nuclear stress when its complement was wh-moved out, and further restrictions seem to be at play. ${ }^{12}$ In this context of these syntactic interactions it would be important to discuss the approach to givenness-movement in Kucerova (2008), but for reasons of space and time that will have to be deferred to a future occasion.

There are a number of additional arguments in favor of the unified approach, apart from the interaction with syntactic environment, that further suggest that givenness-marking and focus/contrast-marking are really the same phonenomenon. They are discussed Wagner $(2005,2006 \mathrm{~b})$ : (i) Givenness-marking and focus-marking correlate, as they are either both present or both absent in languages; (ii) the approach here motivates why, across languages, given material moves to propositional nodes (the left periphery of clauses); (iii) it explains why elements such as something and someone tend to be deaccented in languages that have givenness-/focus-marking, but not in those that don't; (iv); it accounts why pronouns are deaccented in languages that have givenness/focusmarking but not in languages that don't; (v) it can explain the prosody of 'allgiven' cases, which sometimes show the 'neutral' prominence pattern, and sometimes they do not. Alternative approaches have trouble accounting for all-given cases, as we will see below.

12 For example, it seems to be possible to shift prominence to the heads of locative prepositional phrases and also to by in by-phrases (Selkirk, 1984, see also), but not with prepositions that form part of the meaning of the predicate such as in rely on or depend on, although these prepositions can receive the nuclear stress when their complement is wh-moved away. Thanks to Jason Merchant for helpful discussion. 


\subsubsection{Question-Answer Congruence}

Can the new condition on shifting prominence account for question-answer congruence? Consider again the original example:

(1) Question-Answer Congruence (Sentence Focus)

A: Who arrested Smith?

B: The DETECTIVE arrested Smith.

The context here makes available a set of propositions of the form $x$ arrested Smith. The answer picks out the correct answer and rules out others, so the stress shift can be explained in the same way as we would explain it if the context included the statement Sally arrested Smith.

The theory predicts that a prominence shift is possible even if it doesn't match the focus of the question:

(61) Question-Answer Congruence (Sentence Focus)

A: Last week a cop arrested Smith. What happened today?

B: What happened today is that a DETECTIVE arrested Smith.

Although the answer has wide sentence focus, as is indicated by the matrix cleft in B's answer, the prominence can be shifted away from the VP to the subject.

The question remains, however, why asking an explicit question rules out a stress pattern in which the constituent with sentence focus does not contain any accent, even when an appropriate antecedent seems to be available. Consider the following example: ${ }^{13}$

(62) A: Last week a cop arrested Smith. Today a detective came to the store. What did he do?

a. ?\# B: The DETECTIVE arrested Smith.

b. B: The detective arrested SMITH.

One possibility is to say that the question under discussion acts as a filter on $\Delta$, or induces a ranking of what's most salient in $\Delta$ (cf. discussion in Schwarzschild, 1999; Sauerland, 2004). Introducing such a condition on $\Delta$ leaves intact the uniform account of the meaning introduced by shifting prominence based on focus, contrast, and givenness.

13 Note, however, that destressing the given VP is still possible if main prominence does not fall on detective:

[ i.]B: The detective ALSO arrested Smith. 


\subsection{F-Marking}

As illustrated above, accenting certain constituents is sometimes compatible with a focus on bigger constituents that contain them. This phenomenon, discussed already in Chomsky (1971), was named 'Focus Projection' in Höhle $(1982,99)$. Selkirk (1984) developed a formal approach to model this phenomenon, which was updated in Selkirk (1995). ${ }^{14}$

\subsubsection{F-marking}

The theory of F-marking as it is outlined in Selkirk (1995) takes F-markers to be diacritics that are part of the syntactic phrase marker. The focus of a sentence is defined as an F-marked node that is not dominated by another Fmark:

(63) FOCUS (Selkirk, 1995, 555)

The FOCUS of a sentence is defined as an F-marked constituent not dominated by any other F-marked constituent.

One important component of the theory is that the constituent in the answer corresponding to the wh-part of the question at issue has to be a FOCUS, and it has to carry an undominated F-marker.

(64) Focus Condition

An appropriate answer to a wh-question must have an undominated F-mark on the constituent corresponding to the wh-phrase.

In an answer to a question such as What happened next? the root of the sentence has to be a FOCUS, hence it has to be F-marked. Every accented lexical item necessarily carries an F-mark. This is the 'Basic Focus Rule.' These Fmarkers can then be projected to other nodes in the tree. The conventions for F-projection are outlined below:

(65) F-Marking (First Version) (cf. Selkirk, 1995, 555)

Basic Focus Rule: An accented word is F-marked.

\section{F-Projection:}

a. Vertical F-Projection: F-marking of the head of a phrase licenses the F-marking of the phrase.

14 Evidence against the claim that focus projection from the object to the VP is possible is presented in Breen et al. (2009, and references therein). I will not discuss the question whether or not focus projection is actually possible in the way it is assumed in both the

focus-projection account and the reference-set approach in this paper. 
b. Horizontal F-Projection: F-marking of an internal argument of a head licenses the F-marking of the head.

I adopt the terminology 'vertical' and 'horizontal' F-projection from Büring (2003). The example in (66) involves only one accent, the one on the direct object. The first question that arises is why the verb can be non-accented, while this is impossible for the direct object:

(66) After Mary arrived, what happened next?

a. $\quad\left[\text { She }\left[\operatorname{praised}_{F} \mathrm{JOHN}_{F}\right]_{F}\right]_{F}$.

b. \#[ She $\left.\left[\operatorname{PRAISED}_{F} \underline{\text { John }}\right]_{F}\right]_{F}$.

The F-marking of the examples in (66) show an F-marker on the root node, as is required in a context with wide focus, and it obeys the projection conventions. To illustrate how F-marking explains the omissibility of the accent on the verb, consider the way F-markers project (66a):

F-Projection

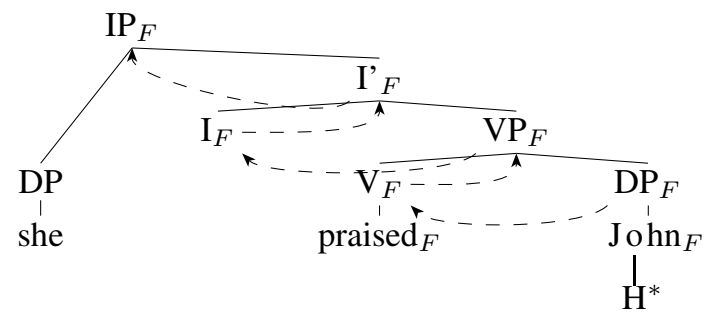

The root of the tree can be F-marked without placing an accent on the predicate, as is required by the Focus-Condition. Based on the Focus-Condition, the example in (66b) should also be acceptable, since placing an accent on the verb allows projection to the root node.

Example (66b) is infelicitous not because of the focus condition, but because one constituent has no F-marker despite the fact that it does not encode given information. In the F-marking system in Selkirk (1995) and Schwarzschild (1999), F-marking interacts with givenness based on the following principle:

(68) Givenness Condition

The absence of F-marking indicates givenness in the discourse.

The only constituent not F-marked in (66a), repeated below, is the subject she:

(66) After Mary arrived, what happened next?

a. [ She $\left.\left[\operatorname{praised}_{F} \operatorname{JoHN}_{F}\right]_{F}\right]_{F}$.

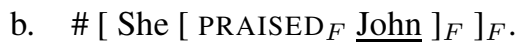


Since it is not accented, it is not F-marked by the basic focus rule, and none of the F-projection rules license an F-mark on the subject. It remains without marking, so therefore it has to be given. This does not cause a problem, since the pronoun of course has to refer to a discourse referent that was mentioned in the question already, so the Givenness-Condition is not violated.

The Givenness-Condition explains that the non-accentuation of the direct object is infelicitous in a context in which it is not given as in (66b). Consider the pattern of F-projection in the case of an unaccented direct object:

(69) F-Projection and Givenness

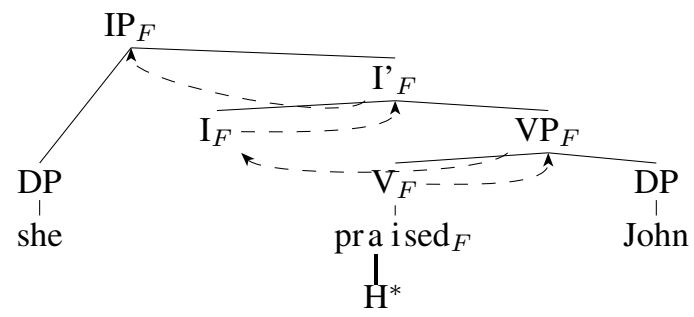

The direct object and the subject remain without F-marking, so both have to be given. The direct object is not given, however, in the context in (66b), hence the structure is infelicitous.

\subsubsection{Some Necessary Revisions}

Consider now the case where the direct object is given:

(70) After John and Mary arrived, what happened next?

a. \#[ She $\left.\left[\operatorname{praised}_{F} \operatorname{JOHN}_{F}\right]_{F}\right]_{F}$.

b. [She $\left.\left[\operatorname{PRAISED}_{F} \underline{\mathrm{John} / \mathrm{him}}\right]_{F}\right]_{F}$.

Here, the lack of the accent on John is acceptable, since the constituent is given. The conditions on givenness do not yet explain why (70a) is infelicitous, however. So far, nothing requires an F-marked constituent NOT to be given.

The addition proposed in Schwarzschild (1999) to fix this problem is that Fmarkers are minimized, that is, if a structure with fewer F-markers is felicitous in a context, an alternative with more F-marking is ungrammatical. ${ }^{15}$

(71) Avoid-F (Schwarzschild, 1999, 156)

F-mark as little as possible, without violating Givenness.

15 Jacobs $(1991,5)$ invokes a similar condition on the minimization of F-marking. F-marking plays out in a different way in the overall theory presented there, although it ultimately serves similar purposes, namely explaining the relation between syntax, focus, and phonology. 
Neither example (70a), with the F-marking in (67), nor example (70b, with the F-marking in (69), violates the Givenness-Condition. But (70a) involves more F-markers; hence it is infelicitous and only (70b) is acceptable.

The Givenness condition and Avoid-F cannot be conflated into a biconditional (a constituent is given if and only if it is not f-marked) because there are cases in which a constituent has to be the FOCUS, but all lexical items inside are given. In this case, one of those items has to be accented and hence F-marked in order to be able to project the F-mark. Hence, given material is sometimes F-marked.

A simple case is that of a given constituent that corresponds to the wh-part of the question at issue (Schwarzschild, 1999). In this case, the Focus Condition requires this condition to be a FOCUS, and hence to contain an F-marker. Then the only candidate for providing the accent that licenses the F-marker is the given item itself:

(72) Who did John's mother praise?

She praised $\operatorname{HIM}_{F}$.

The F-projection rules in Selkirk (1995) need to be further revised, as noted in Schwarzschild (1999) and Büring (2003). Consider a case where the entire VP encodes given information, a type of example also discussed in Jacobs (1988):

(73) Mary praised John. What happened next?

[ ANNA $F$ praised John. ]

The problem that arises is that the F-marking on the subject does not license the F-marking of the entire sentence. One fix for this problem is to revise the projection conventions, and allow vertical projection from any constituent, not just from heads, following Schwarzschild (1999) and Büring (2003). The subject is accented, and the material inside of the VP is not accented, since neither it nor the VP-node itself needs to be F-marked. The most parsimonious Fmarking in tune with the givenness condition in (68) and the focus condition in (64) is the one below, where the F-marker projects up from subject position:

(74) Mary praised John. What happened next?

[ ANNA $F$ praised John. $]_{F}$

The following summarizes the revised convention for vertical projection (Büring, 2003): ${ }^{16}$

16 It is tempting to try and get rid of the notion of vertical F-projection altogether if we restate the givenness condition in the following way: 
(76) F-marking on a constituent licenses F-marking on every dominating node.

\subsubsection{Problems}

One problem with this revised notion of F-marking is that it renders the FocusCondition unnecessary for most cases of question-answer congruence, since now an alternative explanation using the Givenness condition is possible in many instances. For example, the givenness condition and Avoid-F alone can explain the prosody in the following exchange:

(77) A: Who praised John?

B: ANNA $F$ praised John.

This is the only assignment of only one F-marker that does not violate the givenness condition. In fact, the only reason we still need the focus condition is to deal with cases like (72), in which the a given constituent provides the focus of the answer. This duplication of explanations for stress patterns of most cases of question-answer congruence is surely an undesirable redundancy in the theory.

A second problem is that the theory cannot explain why, in so called 'allgiven' contexts, the accent placement that sometimes emerges is the same as in the 'all-new' context. This has already been observed in Schwarzschild (1999) and Büring (2003).

(78) Last week the newspaper reported that after the game all that happened was that the coach praised John. I wonder what happened after this week's game.

a. Again, the coach praised JoHN.

b. \# Again, The COACH praised John.

The fact that in an all-given context the neutral stress pattern emerges cannot be explained by F-projection-neither under the old nor the new projection conventions. Schwarzschild (1999) suggests that the explanation resides in a default stress rule that kicks in only in the case of all-given utterances. The principle that Schwarzschild $(1999,170)$ suggests is the following: ${ }^{17}$

(75) Constituents not containing an F-marker have to be given.

But this is only possible if one also abandons horizontal F-projection, since vertical F-projection feeds horizontal F-projection in the case of multiple predicates, as illustrated in (Wagner, 2005), so we'd end up with a theory without F-projection, such as Rooth (1992).

17 This is equivalent to the principle 'weak head' from Williams (1997). 
(79) Complement Prominence

A head is less prominent than its internal argument(s).

The problem for the F-marking approach is more serious than Schwarzschild (1999) suggests. There must be further principles apart from (79) at play, since all-given cases where the constituent consists of more than just heads and internal arguments are also compatible with the all-new prominence pattern.

But even after conceding these additions, a fundamental property of allgiven contexts remains unexplained. The all-given pattern of relative prominence is the same as that observed in all-new contexts. This seems like a peculiar accident, since the all-new case is derived by F-projection conditions but the 'all-given' case is derived by a completely different set of default rules.

In addition, as discussed in Wagner (2005), it's not always the case that the neutral pattern emerges. Consider the following:

(80) Last week the newspaper reported that after the game all that happened was that the coach or the manager-I forget which--praised John. I wonder what happened after this week's game.

a. \# The coach praised JOHN.

b. The COACH praised John.

The theory of F-marking fails to decide between (80a and b), and moreover it fails to distinguish between contexts that induce 'neutral stress' (78) and cases with 'marked stress' (80). At any intuitive level it is obvious what the crucial factor is: in (78) there is no alternative to the subject, but in (80) there is-but the notion 'alternative' should play no role in this theory.

\subsection{Reference Set Approach}

The reference set approach (Neeleman and Reinhart, 1998; Szendröi, 2001; Reinhart, 2006) is based on prominence, similar to the approach taken by Williams (1997). Default prominence is assumed to be assigned by the nuclear stress rule. Conditions on question-answer congruence can shift around the main prominence in a sentence-this is what accounts for (1). Furthermore, definite noun phrases can undergo anaphoric destressing, which is how this account would deal with the givenness-marking in (3). This section reviews the approach and points out some problems with this division. 


\subsubsection{Destressing and Main Stress Shift}

The phonological representations assumed in Szendröi (2001) and Reinhart (2006) are the annotated syntactic trees from Liberman (1975), now familiar from the discussion of Williams (1997). Default prominence is assigned by the nuclear stress rule. The particular formulation is inspired by Cinque (1993) and works as follows:

(81) Nuclear Stress Rule

Assign a strong label to the node that is syntactically more embedded at every level of the metrical tree. Assign Weak to its sister node.

Placing the nuclear stress determines which foci an expression is compatible with. Every annotated syntactic tree defines a 'focus set,' a set of constituents that can be in focus given the prominence annotation of the representation. Any constituent that contains the main prominence is part of the focus set:

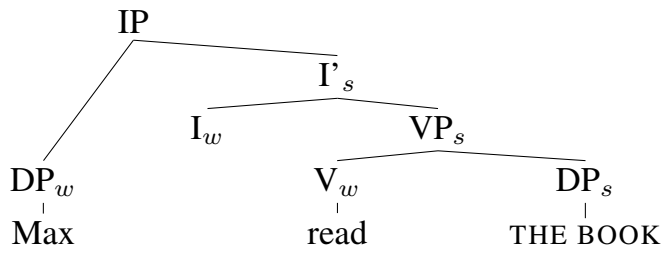

Focus Set: $\left\{\mathrm{DP}_{\text {object }}\right.$, VP, IP $\}$

Conventions about Main and Secondary Stress from Szendröi (2001) are as follows: ${ }^{18}$

(83) a. Main Stress

...falls on the terminal node that is connected to the root node by a path that does not contain any weak nodes, including the root note itself and the terminal node. [...]

b. Secondary Stress

...falls on the terminal node whose path to the root node contains only S nodes, except for exactly one W label on the node immediately dominated by the root node. [...]

The Focus set is now defined as follows:

(84) Focus Set

The focus set of a derivation D comprises all and only subtrees (constituents) which contain the main stress of D.

18 These are two special cases from the tree-to-prominence-level conversion in Liberman and Prince $(1977,259)$ 
There are two operations in addition to the nuclear stress rule that manipulate stress. They do so after the NSR has applied, and, as in Chomsky (1971), they overwrite the original output:

(85) a. Stress Shift (global)

Relocate the main stress on a constituent you want to focus.

b. Destressing (local)

Mark a constituent that is given with ' $\mathrm{w}$ '

Destressing changes the label ' $s$ ' to ' $w$ ' if a node is given. This operation applies locally, and requires evaluating only whether or not a node is given.

(86) 'Destressing' following Szendröi (2001) (cf. Williams (1997))

Assign W to an anaphoric node.

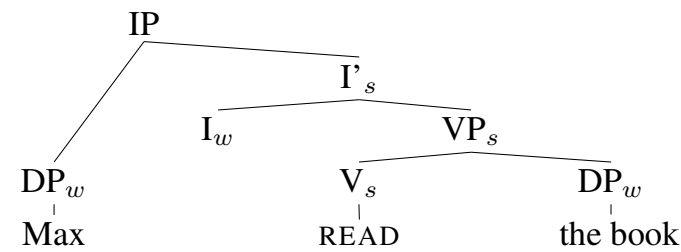

The second operation is called 'main stress shift,' which makes sure that the focus set includes the constituent that is in focus. It operates globally, and can change every label of the tree if necessary.

(87) Main Stress Shift

Assign $\mathrm{S}$ to a node $\alpha$ and every node dominating $\alpha$

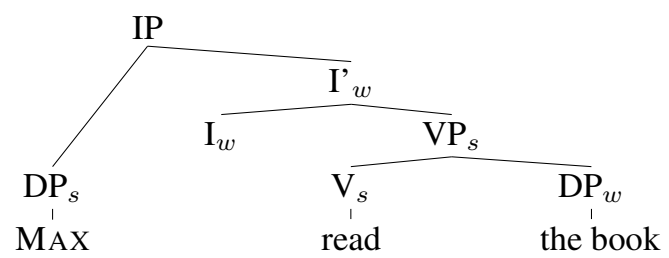

Why is it that the sentence in (87) - according to the Reference Set accountis not compatible with a question with wide focus? Note that the focus set includes IP. The reason that this sentence is ruled out is economy. Economy compares derivations, and selects the most economical derivation compatible with the focus in the context:

(88) Global Economy: Marked and Unmarked Derivations 
a. For a sentence meaning with a certain focus there may be marked and unmarked derivations that express the meaning and whose focus set includes the required focus-marking.

b. Only the most economical element of this set is grammatical.

Stress shift is costly (in fact, each single s-w change in the case of main stress shift is costly).

So now we can see why it is that MAX read a book is not felicitous when the context is just What happened?:

(89) Example
a. Less costly: Max read a BOOK. $\left\{\mathrm{DP}_{\text {object }}, \mathrm{VP}, \mathrm{IP}\right\}$
b. More Costly: MAX read a book. $\left\{\mathrm{DP}_{\text {subject }}, \mathrm{IP}\right\}$
$\rightarrow$

Utterance (83b) can only be used for $\mathrm{DP}_{\text {subject }}$ focus, since (83a) is more economical and can encode IP focus

The sentence Max read a BОOK blocks MAX read a book as a sentence conveying sentence-wide focus, since it does not involve stress shift and is hence more economical. Stress shift is an operation that, according to Reinhart (2006), is 'illicit' and hence costly, but nevertheless it is sometimes necessary. A context that requires subject focus induces stress shift to the subject. The more economical derivation without stress-shift leads to a representation of the sentence that does not include the subject in its focus set. This kind of reasoning requires a comparison between derivations and their focus sets, and this comparison set is called a 'reference set.'

It is not clear why main stress shift is costly but anaphoric destressing is not. It is also not clear why anaphoric destressing should be obligatory when possible, just as it is not explained why main stress shift for sentence focus should be obligatory. Whatever the explanation is, the reference set approach has to give two separate explanations for these two generalizations.

An empirical problem for the reference set is the fact that, contrary to Reinhart (2006), marked prominence is often compatible with wide focus even in cases that should be ruled out by economy. But sometimes shifting prominence to the subject is possible, and in fact obligatory, in contexts that require wide focus, a fact observed already in Jacobs (1988) based on German data. Consider:

(90) A: Last week, there was a lot of noise because Bill was building a desk. What's the noise today?

a. \# B: [ ${ }_{F}$ My neighbour is building a DESK $]$. 
b. B: [F MY NEIGHBOUR is building a desk].

There are two possible ways to modify the reference set approach to account for such examples. (i) Generalizing Anaphoric Destressing: Any constituent can destress if there is an appropriate antecedent-not just definite referring expressions as Reinhart (2006) posited; (ii) Generalizing Main Stress Shift: the sentences in which VPs and indefinites appear to destress really contain nested foci, and stress shift needs to be redefined so as to be sensitive to local foci embedded in the structure.

Looking at each option in turn, we will see that the revisions required to generalize either anaphoric destressing or main stress shift will turn them into the equivalent of local alternatives, and will render the other operation redundant.

\subsubsection{Generalizing Main Stress Shift}

This option seems more promising, and in fact is pursued based on a related example in Neeleman and Szendröi (2004). It turns out however, that the steps necessary to make this work would require modifying main stress shift in such a way that it becomes equivalent to the local alternatives approach.

(91) Father: What happened?

Mother: You know how I think our children should read decent books. Well, when I came home, rather than doing his homework, [IP Johnny was [VP reading [DP SUPERMAN] to some kid]].

The idea is that the mother is contrasting Superman with more decent books (those by Kafka are mentioned) and is thus focused. This focus has the effect that stress shift takes place, the operation that is usually only triggered by sentence stress. So main stress shift is generalized, and the prominence between the subject and the VP is flipped.

Note that even with the shifted prominence the entire sentence is in the focus set, but usually, wide focus would be blocked by economy. In the present case, it shouldn't be blocked. The way in which Neeleman and Szendröi (2004) achieve this is by modifying the theory in the following way: (i) there can be multiple main stresses in a sentence (presumably all connected by nodes labeled $s$ up to the root); (ii) they propose a new focus condition: any focus, embedded or not, must have main stress; and (iii), there is an economy condition that minimizes the number of main stresses ('prosodic peaks'). The representation with main stress on to some kid and no main stress on Superman is ruled out by the new focus condition. A representation with main stress both on $\mathrm{Su}$ perman and to some kid is ruled out by peak economy. So given the conveyed meaning, the pronunciation in (91) is optimal. 
We can apply the same logic to the example in 90 . In the analysis of Neeleman and Szendröi (2004), this pronuncation does not necessarily require sentence focus on the subject, it simply requires a some constituent that contrasts with the subject:

(92) ${ }_{F}$ MY NEIGHBOUR $_{F}$ is building a desk $]$.

However, it is in fact not sufficient that there is an antecedent constituent that could contrast with the subject, but the antecedent itself has to contain a parallel VP:

(93) A: Last week, Bill was visiting. What's going on this week?

B: \# [ ${ }_{F}$ MY NEIGHBOUR is building a desk].

As we already saw, shifting prominence to the subject actually requires an alternative $a^{\prime}$ to the subject such that $\left[a^{\prime} \mathrm{VP}\right]$ is salient. In other words, for main stress shift to apply it is not sufficient that a constituent be focused: its sister must be given relative to it, and we need an antecedent of the form $x$ building a desk. This is completely unexpected under the analysis of Neeleman and Szendröi (2004).

Let's reconsider the example in 91. There is no reason to think that this case should work differently. And in this case, contrary to Neeleman and Szendröi (2004), what the mother must actually be conveying with the prosody in (91) is not just a contrast between Superman books and Kafka books, but between reading Superman books to some kid and reading Kafka books to some kid. In the local alternatives approach we could analyze this example as having the constituent 'read $\mathrm{x}$ to some kid' being marked as given relative to the 'Superman. ${ }^{19}$

Is it plausible, though, that the father in this dialogue can accommodate a relevant antecedent in the present context, rather than just the contrast between Superman and Kafka that Neeleman and Szendröi (2004) argue is accommodated here? Let's test this based on the already familiar case of shifting prominence in [ Subject VP ]. A prominence shift is also possible in the following example which is similar in flavour to 91-I'm borrowing the negative view of Superman comics from the original example:

(94) Father: What happened?

Mother: I thought good fiction is valued in the country. Well, I just read that A SUPERMAN comic made the best seller list.

19 This would presumably require movement of 'Superman' to create the right constituent structure. 
Prominence shift is quite possible here, indicating that the antecedent statement can be accommodated, that is, the alternatives relevant here are entire propositions of the form $\{$ A Superman comic made the best seller list $\}$., A serious novel made the best seller list, $\}$. We know this because in the case of shifting away prominence from the VP to the subject we already saw that it is not sufficient to merely have an alternative for the subject, based on examples such as (93). The VP is marked as given relative to the subject, and it's no problem to accommodate an antecedent here. It is thus clear that that the antecedent predicted by the local alterantives approach for 91 should also be easy to accommodate, so this approach has no problem accounting for Neeleman and Szendröi (2004)'s case, but conversely Neeleman and Szendröi (2004) make the wrong prediction for the case of shifting prominence to the subject.

We conclude that main stress shift is only licensed under a condition that takes into account the material that prominence is shifted away from. So we actually need a condition on stress shift that is equivalent to the condition on prominence shift in the local alternatives approach. The example in (91) is misleading, since it does not reveal that there is more at play than just focus on Superman. ${ }^{20}$

This strengthened condition needed to account for these examples is equivalent to one proposed in the local alternatives approach. If it is true that this condition can also handle anaphoric destressing and question-answer congruence, as was argued in the previous part of the paper, then the other ingredients of the reference set approach have become redundant once this revision is incorporated.

\subsubsection{Generalizing Anaphoric Destressing}

Suppose we go with the other option, and let anaphoric destressing apply to constituents other than definite referring expressions. First, we run into a duplication problem: There are now two different explanations for many sentential stress patterns. For example, now there are two ways to account for the stress pattern in many questions: main stress shift and destressing. Destressing of given material alone is sufficient as an explanation for why the VP is not stressed in the following example:

(95) A: Who is building a desk?

20 In both $(91,94)$ one can also not deaccent. The constituent to some kid, however, makes the accommodation particularly easy, but if we substitute to a stranger it might make deaccenting less likely - this difference is unexpected if all that matters is the focus on Superman. It is not clear that an accent on stranger in such a case would require an additional focus on that constituent, as suggested in Neeleman and Szendröi (2004). 
a. \# B[F My neighbour] is building a DESK.

b. B: $[F$ MY NEIGHBOUR] is building a desk.

Similarly, a question that places focus on the verb makes the indefinite object given, and hence the lack of stress on it can be explained by destressing and without invoking main stress shift:

(96) A: What did you say your neighbour is doing with a desk?

a. \# B: My neighbour is ${ }_{F}$ building] a DESK.

b. B: My neighbour is $[F$ BUILDING] a desk.

In other words, main stress shift is unnecessary to account for the crucial cases by which it was motivated in the first place.

This solution is unsatisfactory for a second reason. As we saw, shifting the prominence from the VP is not possible just because the VP is given. The subject has to be a true alternative for it to be licensed, so the anaphoric destressing would impose too weak a condition on it. This would be completely unexpected if the VP could simply be anaphorically destressed. Therefore, the condition on anaphoric destressing needs to be strengthened such that we take into account the sister of the anaphorically destressed constituent, and require local exclusive alternatives for the entire node-again. Again, the theory has morphed into the local exclusive alternatives approach.

\subsubsection{Indefinites}

Another claim about constraint on anaphoric destressing in Reinhart (2006) is that indefinites cannot undergo it. This is unexpected under the local alternatives approach. The claim is that indefinites can lose stress only by virtue of main stress shift. In the appropriate context, however, they can destress, and yet the sentence occurs in a wide-focus context:

(97) A: Last time I saw her, your neighbour was looking for a desk at a yard sale. What's she doing these days?

a. \# B: What's she's doing these days is she [F 's building a DESK].

b. B: What's she's doing these days is she [ $F$ is BUILDING a desk].

Destressing of indefinites and entire VPs exists, and is compatible with wide focus. In this particular example, it could very well be that building is focused since an alternative is salient, looking for at a yard sale, and even buying can be inferred as a possible contrast.

The key question, however, is this: Is it necessary that there is such a salient alternative to the predicate? Consider the following classic examples: 
(98) a. Has John read Slaughterhouse-Five?

He doesn't READ books. (cf. Ladd, 1980, 81)

b. I bought a painting last week.

I really LIKE paintings. (cf. Chafe, 1976, 32)

Also in the following examples, it is not clear that alternatives to the adjacent predicate are invoked:

(99) a. A: Do you want to eat something?

B: I've already HAD some food.

b. A: Why don't you bring a friend?

B: You know that I don't HAVE any friends.

c. A: She's going to the theatre again?

B: She really LIKES plays.

d. A: Why don't they produce brussels sprouts?

B: Nobody BUYS brussels sprouts.

e. A: Why is she dressed up as a vampire?

B: She just read a BOOK about vampires

In all of the above examples, it seems that the indefinite can be deaccented just by virtue of the fact that it was made salient by context.

What do these utterances have in common? While the focus of these utterances is wide, a plausible alternative set of the respective answers would involve statements about brussels sprouts, plays, friends, or food respectively. The alternative set evoked in (99e) is of the form $\lambda x . p(x)$ [vampires].

These responses are all statements about the set denoted by the indefinite predicate, and in that sense they are quite parallel to the case of a referring expression that is unaccented like Smith. So why is it more difficult to omit the accent on an indefinite? Maybe it's just more likely that we look at a situation considering alternative sets defined based on individuals (What about Smith?) rather than defined based on a predicate (What about brussels sprouts?).

In sum, the reference set approach cannot account for the data discussed here- unless we revise it in such a way that it becomes equivalent to the local alternatives approach.

There are many other proposals that would require a closer look at this point for further comparisons of similarities and differences, for example, the approach in Jacobs (1991), who proposes a theory of focus and considers how it affects prominence relations on metrically annotated trees, a precedent for the theories discussed in this paper. In addition to specifying how sentence focus and contrast affects prosody, it marks certain elements as lexically nonstressable (pronouns and elements such as something), or non-stressable by 
virtue of their being given in context. Again, this introduces different explanations for facts that are taken to be reflexes of the same phenomenon here. A more in-depth discussion will have to wait for a future occasion.

\subsection{Conclusion: Local Exclusive Alternatives}

This paper has examined three types of factors that affect accent placementquestion-answer congruence, contrast and givenness-and elaborates arguments in favor of the position that all three should be treated as aspects of the same phenomenon, rather than positing two or more separate mechanisms that account for them.

The upshot of the 'local alternatives' approach outlined in this paper is that in addition to whichever principle(s) negotiate default stress, there is another principle that allows the switching of prominence relations at any node. Whenever prominence is flipped on a node, an alternative is evoked on the now strong sister such that the node consisting of that alternative paired with the now weak constituent, the given one, should be salient in the discourse, and this alternative has to be a true alternative. Whether or not an alternative is a 'true' alternative is tested by checking whether an alternative statement is excluded, with the help of an exhaustive operator.

A unified account based on local alternatives was compared to alternative approaches, the F-projection account (Selkirk, 1995), the Reference Set Approach (Reinhart, 2006), and the disanaphora approach (Williams, 1997). Each involves two separate mechanisms, one for dealing with givenness-marking, and one for dealing with contrast and focus. Various problems were pointed out, and furthermore the premise that givenness-marking and focus are separate phenomena was argued to be false.

Information structure effects in English seem to be driven by what entities are salient in discourse, and not necessarily by what is asserted to be true or false. Why would a language code givenness and focus in this way, purely indicating that a contrast is available in the context, but without necessarily making that contrast part of what is asserted?

Ultimately, understanding why focus-marking works in the way it works will require an understanding of how sentences are processed and integrated into the listener's model of the discourse. Shifting prominence does not merely require the constituent from which prominence is shifted away to be accessible or given in the context, it also requires a contrasting alternative for its sister. This complex anaphoric relation to an antecedent may help to tie in the new utterance in the discourse, by linking it to salient information previously men- 
tioned or assumed as part of the background of the new statement. Understanding what a sentence means being able to grasp its contribution to the discourse context, and maybe anaphoric relations of the kind introduced by prominence shifts help to enforce this link. This paper only gives arguments that English works in the way it does, but does not offer a deeper explanation of why that would be the case. A better understanding of how information structuring in English aids processing may provide a rationalization.

The assumption of this paper (and the semantic literature on givenness and focus more generally) has been that shifting prominence is categorical. I have argued that it encodes a presupposition, i.e. a restriction on the context and what is taken to be the 'Common Ground' (Stalnaker, 1978; Clark, 1994), and this particular presupposition encodes a presupposition about what has to be salient in the discourse. But salience itself is likely to be a gradient notion, and the prominence of a constituent may gradiently vary depending on the degree of salience. There is a line of research that looks at 'givenness' effects based on the notion of 'predictability' Prince (cf. 1981, for different notions of givenness), and is designed to model quantitative effects of givenness. Bard et al. (2000)), for example, report that in addition to deaccentuation, reducing token length and decreasing articulatory detail is also a gradient reflex of givenness. Constituents that are accented and thus not marked as given might still be subject to such gradient reduction effects when they are contextually salient and 'predictable' (Jurafsky et al., 2001). The prediction of the theory outlined here is the following: renditions of a constituent may be shorter and less articulated depending on the degree that the constituent is accessible in the context; but a prominence shift can only occur when the presupposition of the related to the local exclusive alternatives is fulfilled.

\section{Acknowledgements}

Thanks to the audience at the UCL Workshop and to an anonymous reviewer for helpful comments. I am also indebted to Jon Gajewski, James German, Kyle Johnson, Roni Katzir, and Jason Merchant and for discussions of some the ideas in this paper.

\section{References}

Allerton, DJ. 1978. The notion of "givenness" and its relations to presupposition and to theme. Lingua Amsterdam 44:133-168.

Altmann, Hans, ed. 1988. Intonationsforschungen. Tübingen: Niemeyer.

Bader, Christopher. 2001. Givenness, focus, and prosody. Doctoral Dissertation, MIT. 
Bard, Ellen Gurman, Anne H. Anderson, Catherine Sotillo, Matthew Aylett, Gwyneth Doherty-Sneddon, and Alison Newlands. 2000. Controlling the intelligibility of referring expressions in dialogue. Journal of Memory and Language 42:1-22.

Bierwisch, Manfred. 1966a. Regeln für die Intonation deutscher Sätze. In Bierwisch (1966b), 99-201.

Bierwisch, Manfred, ed. 1966b. Untersuchungen über den deutschen Akzent, volume 7 of Studia Grammatika. Berlin: Akademie Verlag.

Breen, Mara, Evelina Fedorenko, Michael Wagner, and Edward Gibson. 2009. Acoustic correlates of information structure. Under Revision.

Büring, Daniel. 2003. Focus projection and default prominence. In Proceedings, ed. Valéria Molnár and Susanne Winkler. Berlin: Mouton De Gruyter.

Büring, Daniel. 2008. What's new (and what's given) in the theory of focus? BLS Proceedings.

Chafe, Wallace L. 1976. Givenness, contrastiveness, definiteness, subjects and topics. In Subject and topic, ed. Charles N. Li, 25-56. New York: Academic Press.

Chomsky, Noam. 1971. Deep structure, surface structure, and semantic interpretation. In Semantics: An interdisciplinary reader in philosophy, linguistics, and psychology, ed. D.D. Steinberg and L.A. Jakobovits. Cambridge: Cambridge University Press.

Chomsky, Noam, and Morris Halle. 1968. The sound pattern of English. New York: Harper \& Row.

Cinque, Guglielmo. 1993. A null-theory of phrase and compound stress. Linguistic Inquiry 24:239-298.

Clark, H. H., and S.E. Haviland. 1977. Comprehension and the given-new contract. In Discourse production and comprehension, ed. R. O. Freedle, 1-40. Hillsdale: Erlbaum.

Clark, Herb H. 1994. Discourse in production. In Handbook of psycholinguistics, ed. M.A. Gernsbacher. San Diego: Academic Press.

Fox, Danny. 2006. Free choice and the theory of scalar implicatures. Unpublished ms., MIT.

Geurts, Bart, and Rob van der Sandt. 2004. Interpreting focus. Theoretical Linguistics 30:1-44.

Goldsmith, John A., ed. 1995. The handbook of phonological theory. London: Blackwell.

Gussenhoven, Carlos. 1984. On the grammar and semantics of sentence accents. Dordrecht: Foris.

Halliday, M.A.K. 1967. Notes on transitivity and theme in English, part 2. Journal of Linguistics 3:199-244.

Hamblin, C. L. 1973. Questions in Montague english. Foundations of language 41-53.

Hankamer, Jorge, and Ivan Sag. 1976. Deep and surface anaphora. Linguistic Inquiry 7:291-428.

Haviland, S.E., and H.H. Clark. 1974. What's new? Acquiring new information as a process in comprehension. Journal of Verbal Learning \& Verbal Behavior. Vol 13:512-521.

Heim, Irene. 1982. The semantics of definite and indefinite noun phrases. Doctoral Dissertation, University of Massachussetts, Amherst. 
Heim, Irene. 1991. Artikel und Definitheit. In von Stechow and Wunderlich (1991), 487-535.

Höhle, Tilman. 1982. Explikation für 'Normale Betonung' und 'Normale Wortstellung'. In Satzglieder des Deutschen, ed. Werner Abaraham, 75-153. Narr.

Jackendoff, Ray S. 1972. Semantic interpretation in generative grammar. Cambridge, Ma.: MIT Press.

Jacobs, Joachim. 1988. Fokus-Hintergrund-Gliederung und Grammatik. In Altmann (1988), 89-134.

Jacobs, Joachim. 1991. Focus ambiguities. Journal of Semantics 8:1-36.

Jacobs, Joachim. 2004. Focus, presuppositions, and discourse restrictions. Theoretical Linguistics 30:99-110.

Jurafsky, Dan, Alan Bell, Michelle Gregory, and William D. Raymond. 2001. Probabilistic relations between words: Evidence from reduction in lexical production. In Frequency in the emergence of linguistic structure, ed. Joan Bybee and Paul Hopper, 229-254. Amsterdam: John Benjamins.

Kamp, Hans. 1981. A theory of truth and semantic representation. In Formal methods in the study of language, ed. Jeroen Groenendijk, 277-322. Amsterdam: Mathematical Centre Tracts.

Kiparsky, Paul. 1966. Über den deutschen Wortakzent. In Bierwisch (1966b), 71-98.

Kratzer, Angelika, and Elisabeth Selkirk. 2004. Class notes. UMass Amherst.

Krifka, Manfred. 1984. Fokus, Topik, syntaktische Struktur und semantische Interpretation. Universität Tübingen.

Kucerova, Ivona. 2008. Givenness and maximize presupposition. In Proceedings of SuB12, ed. Atle Grø nn, 353-366. Oslo.

Ladd, D. Robert. 1980. The structure of intonational meaning. Bloomington: Indiana University Press.

Liberman, Mark Y. 1975. The intonational system of English. Doctoral Dissertation, MIT.

Liberman, Mark Y., and Alan S. Prince. 1977. On stress and linguistic rhythm. Linguistic Inquiry 8:249-336.

Neeleman, Ad, and Tania Reinhart. 1998. Scrambling and the PF-interface. In The projection of arguments, ed. Miriam Butt and Wilhelm Geuder, 309-353. CSLI.

Neeleman, Ad, and Kriszta Szendröi. 2004. Superman sentences. Linguistic Inquiry 35:149-159.

Prince, Ellen. 1981. Toward a taxonomy of given-new information. In Radical pragmatics, ed. Peter Cole, 223-255. New York: Academic Press.

Reinhart, Tanya. 2006. Interface strategies. Cambridge, Ma.: MIT Press.

Rizzi, Luigi. 1997. The fine structure of the left periphery. In Elements of grammar, ed. Liliane Haegeman. Kluwer.

Rochemont, Michael. 1986. Focus in generative grammar. Amsterdam/Philadelphia: John Benjamins.

Rooth, Mats. 1992. A theory of focus interpretation. Natural Language Semantics $1: 75-116$.

Rooth, Mats. 2007. Entailment and local alternative semantics for focus. Ms. Cornell University. 
Sauerland, Uli. 2004. Do not interpret focus! Why a presuppositional account of focus fails, and how a presuppositional account of givenness works. In Proceedings of sinn und bedeutung 9, university of nijmegen, ed. E. Maier, C. Bary, and J. Huitink, $370-384$.

Schmerling, S. F. 1976. Aspects of English sentence stress. Austin: University of Texas. Schwarzschild, Roger. 1997. Interpreting accent. Ms. Rutgers University.

Schwarzschild, Roger. 1999. Givenness, AVOIDF and other constraints on the placement of accent. Natural Language Semantics 7:141-177.

Selkirk, Elisabeth O. 1984. Phonology and syntax. The relation between sound and structure. Cambridge, MA: MIT Press.

Selkirk, Elizabeth O. 1995. Sentence prosody: Intonation, stress, and phrasing. In Goldsmith (1995), 550-569.

Stalnaker, R. 1978. Assertion. Syntax and Semantics 9:315-332.

Stalnaker, R. 2002. Common Ground. Linguistics and Philosophy 25:701-721.

von Stechow, Arnim, and Dieter Wunderlich, ed. 1991. Semantik. Ein internationales Handbuch der zeitgenössischen Forschung. (HSK 6). Berlin: de Gruyter.

Szendröi, Kriszta. 2001. Focus and the syntax-phonology interface. Doctoral Dissertation, University College London.

Wagner, Michael. 2005. Prosody and recursion. Doctoral Dissertation, MIT.

Wagner, Michael. 2006a. Association by movement. Evidence from NPI-licensing. Natural Language Semantics 14:297-324.

Wagner, Michael. 2006b. Givenness and locality. In Proceedings of SALT XVI, ed. Masayuki Gibson and Jonathan Howell, 295-312. Ithaca, NY: CLC Publications.

Wagner, Michael. 2007. A note on stress in intransitives in English. Snippets 16.

Wagner, Michael. 2009. Focus, topic, and word order: A compositional view. In Alternatives to cartography. Jeroen van Craenenbroeck.

Walker, Marylin A., Aravind K. Joshi, and Ellen F. Prince. 1998. Centering in naturally occurring discourse: An overview. In Centering theory in discourse, ed. M.A. Walker, A.K. Joshi, and E.F. Prince, 1-30. Oxford: Clarendon.

Williams, Edwin. 1997. Blocking and anaphora. Linguistic Inquiry 28:577-628. 